\title{
Exploration of Antibacterial Metabolites Producing Marine Bacteria from Sundarbans, Bangladesh
}

\author{
Ashish Kumar Sarker ${ }^{1}$, Md. Anwarul Haque ${ }^{1}$, Mohammad Sayful Islam², \\ Md. Ajijur Rahman ${ }^{2}$ and Md. Anwar UI Islam² \\ ${ }^{1}$ Department of Pharmacy, Pabna University of Science and Technology, Pabna-6600, Bangladesh \\ ${ }^{2}$ Department of Pharmacy, University of Rajshahi, Rajshahi-6205, Bangladesh
}

Received: December 31, 2014; Accepted: January 28, 2015

\begin{abstract}
To combat the increasing numbers of antibiotic resistant strains of pathogenic bacteria new source of antibacterial agents are desperately needed. This study was aimed to discover new marine bacteria having antibacterial activity from marine soil samples of Sundarbans, Bangladesh. Using starch-casein-nitrate-agar medium thirty nine marine bacteria colonies were isolated as pure isolates from nine marine soil samples. Each of the isolates was preserved in both short term and long term basis. Based on the aerial and substrate mycelia color of the isolates they were grouped into five color series and were screened for their antibacterial activity against a series of test bacteria. Among thirty nine pure isolates twenty four isolates (61.5\%) exhibited moderate to high activity against three grampositive and four gram-negative bacteria. This is due to the antibacterial metabolites secreted in the medium by most of the isolates. It suggested that Sundarbans may be an interesting, valuable and potential source for the exploration of novel marine bacteria with the potential to yield useful new antibacterial secondary metabolites of pharmaceutical interest.
\end{abstract}

Key words: Marine bacteria, Antibacterial, Secondary metabolites, Isolation, Sundarbans

\section{Introduction}

Bacterial resistance to antimicrobial agents is a threat and biggest challenges to public health over the world. The incidence of antimicrobial resistance among microorganisms is increasing at a shocking rate worldwide. The consequences of resistance not only affect our ability to treat infection but also affect duration of treatment, threaten health security, damage trade and economics (Singer et al., 2003). Microorganisms acquire resistance towards common antibiotics by altering their metabolism and genetic structure (Raghunath, 2008, Maragakis et al., 2008). Due to escalation of drug resistance the requirement of advance antimicrobial agents having potential activity towards resistance bacteria (Guskey et al., 2010) has been emphasized.

Nature is always infinite source for important microorganism producing novel compounds having antagonistic activity against pathogenic microorganisms. Actinobacteria are fruitful producers of thousands of biologically active secondary metabolites. Terrestrial for actinobacteria producing many important antibiotics, anticancer, antitumor and immunosuppressive agents (Manivasagan et al., 2014). But in the recent years, frequent repetition of the same compounds from the terrestrial actinobacteria has made them less attractive for screening programs. That is why much attention has been focused on screening of microorganism from diverse environments for their ability to produce new secondary metabolites.

Unexplored environments are often appealing to researchers due to occurrence of novel bacteria (Nawani et al., 2013). The ocean remains as an unexploited source for many drugs and pharmacologically active substances (Sivasubramanian et al., 2011). For future drug discovery, the isolation and extraction of novel bioactive secondary metabolites from marine microorganisms have a biomedical potential as the oceans cover $70 \%$ of the planet's surface. It harbors a vast variety of marine organisms that are diverse in their physiology and adaptations (Bhatnagar

Correspondence to: Md. Anwar U1 Islam, Email: profanwarulislam@yahoo.com

sources have been studied and screened since the 1950s et al., 2010). In the past, the ecological role of 
actinobacteria in the marine ecosystem was largely neglected and little focus had been given to isolate marine strains for the discovery of new drugs (Manivasagan et al., 2013). But now due to advancement in science and medical technology, more importance has been given to identify new bioactive metabolites synthesized by actinobacteria from various marine sources.

Marine actinobacteriology is one of the major emerging areas of research in topics. Marine actinobacteria are economically as well as biotechnologically valuable prokaryotes (Manivasagan et al., 2013). They are particularly attractive because they have high potency required for bioactive compounds to be effective in the marine environment, due to the diluting effect of sea water (Valli et al., 2012). Thousands of novel compounds have been isolated from various marine bacteria and tested for pharmacological properties, many of which are commercially available. Many more are being tested as potential bioactive compound at the preclinical and clinical stages (Jaiganesh et al., 2012). At present time, actinobacteria isolated from the marine environment have received much attention due to the structural diversity and unique biological properties of their secondary compounds. They are efficient producers of new secondary metabolites that show a range of biological activities including antibacterial, antifungal, anticancer, antitumor, cytotoxic, cytostatic, anti-inflammatory, anti-parasitic, anti-malaria, antiviral, antioxidant, anti-angiogenesis, etc (Manivasagan et al., 2014). Among the actinobacteria, streptomycetes group are considered economically important because out of the approximately more than 10,000 known antibiotics (Manivasagan et al., 2013), 80\% are produced by this genus, with other genera trailing. Streptomyces is the largest genus of the actinobacteria and are gram- positive with high GC content (Kampfer, 2006). They include filamentous bacteria which produce well developed vegetative hyphae with branches.

The mangrove ecosystem is a largely unexplored source for Actinomycetes with the potential to produce biologically active secondary metabolites (Hong et al., 2009). Actinomycetes isolated from mangrove habitats are potentially rich source for the discovery of antibacterial, anti-infection and anti-tumor compounds, anti-diabetes and neurodegenerative agents (Hong et al., 2009).
Sundarbans is the largest mangrove forest in the world, and covers areas of India and Bangladesh $(140,000$ ha). Sundarbans is intersected by a complex network of tidal waterways, mudflats and small islands of salt-tolerant mangrove forests. The forest is unique for its agro environmental condition and its soil is routinely or occasionally inundated with low, moderate or high saline water (Arifuzzaman et al., 2010). Among thirty two genera of Actinomycetes, Sundarbans soil is rich in Actinomyces, Micromonospora, Nocardia and Streptomyces (Arifuzzaman et al., 2010).

A few studies have been done so far using Sundarbans soils to screen new bacteria for new bioactive compounds. Our investigation was aimed to screen marine bacteria from Sundarbans soil having capability to produce antibacterial compounds.

\section{Materials and Methods}

Marine soil samples collection: From the different location of Sundarbans, Bangladesh, nine marine soil samples were collected. Using some clean, dry and sterile small plastic tubes along with sterile spatula, marking pen for proper labeling of the date of collection, rubber band and other accessories marine soil samples (approx. $500 \mathrm{~g}$ ) were collected. The collection of marine soil was carefully done for documentation of varying characteristics of the points of collection as regard to the organic matter, moisture content, particle size, presence of saline water and color of marine soil. Soil samples were collected from the marine region (containing saline water) of Sundarbans. Marine soil samples were collected at the specific depth of the earth surface which ranges from layers just below the upper surface to 1 meter depth. The collected marine soil samples were dried in a hot air oven at $60-70{ }^{\circ} \mathrm{C}$ for 3 hours and stored at $4^{\circ} \mathrm{C}$ in refrigerator until further research work.

Isolation of pure culture of bacteria: By using standard microbiological method (spread plate technique) thirty nine bacteria strains were isolated and obtained as pure culture. For the isolation of pure bacteria, serial dilutions of marine soil suspensions were prepared by ten-fold dilution methods (Nonomura et al., 1969) to obtain suitable dilution of number of test tubes so that individual bacteria become separated far enough apart. In this method, $1 \mathrm{~g}$ of dried soil was suspended in $9 \mathrm{ml}$ sterile water, and con- 
secutive serial dilutions were made by transferring $1 \mathrm{ml}$ of aliquots to 2 nd test tube containing $9 \mathrm{ml}$ of sterile water, and in this way dilution was carried out up to $10^{4}$ times. Uniform suspensions of the contents were produced each time by using vortex. An aliquot of $0.1 \mathrm{ml}$ of each dilution was taken carefully and spread uniformly over the surface of starch-casein nitrate-agar medium containing cycloheximide $(100 \mu \mathrm{g} / \mathrm{ml})$ on $16 \mathrm{~cm}$ petri dishes. Plates were incubated at $31^{\circ} \mathrm{C}$ and monitored for 7 days. The colonies were carefully counted by visual observation. Plates with more colonies (100-125) colonies were selected for further isolation in pure culture. The colonies those showed Streptomyces like appearance under light microscope were recultivated several times to purify.

Preservation of the pure isolates: For short time preservation of purified bacteria yeast-extract-glucoseagar slants were used. The bacteria were inoculated in yeast-extract-glucose-agar slants using a sterile loop and incubated at $31^{\circ} \mathrm{C}$ for 3 or 4 days. Then the yeast-extractglucose-agar slants containing purified bacteria were kept in a refrigerator at $4^{\circ} \mathrm{C}$ for short time storage (two months). For long term preservation the expected bacterial colony were collected from subculture or purification plate by sterile inoculating loop, adequately mixed by vortex mixer and isolates were kept at $-20{ }^{\circ} \mathrm{C}$ in the presence of glycerol $(15 \% \mathrm{v} / \mathrm{v})$.

Color grouping of the pure isolate: The color of the aerial mycelia, substrate mycelia and soluble pigment were determined based on the National Bureau of Standards Color Chart (Zhao et al., 2006) and all the pure marine bacteria were grouped into five different color series. The color of the aerial mycelia, substrate mycelia and pigment production by the isolates were examined on yeast-extract-glucose-agar plates after 7 days of incubation period at $31^{\circ} \mathrm{C}$.

Screening of antimicrobial activities of pure isolates: Primary screening of isolates were performed for antibacterial activity by streak-plating technique on yeast-extractglucose-agar medium (Alcamo et al., 2004). Each pure isolates were inoculated individually in straight line on different agar plates and incubated at $31^{\circ} \mathrm{C}$ for 5 days for allowing the isolates to secrete antibacterial metabolites into the medium. After the incubation period, properly diluted test organisms were cross streaked on the same plate in perpendicular manner. Then the plates were incubated at $31^{\circ} \mathrm{C}$ for 24 hours. The plates were examined for the zone of inhibition against test organisms using a millimeter scale (Shomura et al., 1980).

Test organisms: The test organisms used for the study were gram-positive bacteria: Staphylococcus aureus ATCC-259233, Streptococcus agalactiae and Bacillus cereus; gram-negative bacteria: Escherichia coli FPFC1407, Shigella dysenteriae AL-35587, Shigella sonnei and Pseudomonas aeruginosa. The test organisms were obtained from the stocks of the Pharmaceutical Microbiology Laboratory of the Department of Pharmacy, Faculty of Sciences, University of Rajshahi, Bangladesh. They were maintained in nutrient agar slants at $4^{\circ} \mathrm{C}$.

\section{Results and Discussion}

All purified isolates were preserved on yeast-extractglucose-agar media and each of the isolates exhibited morphology of typical Streptomyces. The colonies were slow growing, aerobic, glabrous or chalky, folded, and with aerial and substrate mycelia of different colors (Anderson et al., 2001). All these isolates were gram-positive and fitted to the description of genus Streptomyces in Bergey's Manual of Systemic Bacteriology. All these isolates were classified into five color series based on the color of the aerial mycelia, substrate mycelia and soluble pigment (Table 1 and 2). Among the five series of the isolates, orange series $(30.7 \%)$ and gray series $(28.2 \%)$ isolates were more prime. Out of 39 isolates, four isolates (ANAM-5, ANAM-38, ANAM-39 and ANAM-40) produced diffusible pigments in the media (Table 1 and 2).

Using streak-plating technique all the isolated marine bacteria strains were screened for their antibacterial activity (Table 3 and 4, Figure 1, 2 and 3). Out of thirty nine pure marine isolates twenty four isolates $(61.5 \%)$ exhibited a broad range of antibacterial activity. Spectrums of antibacterial activity of different color group of isolates were different. Antibacterial activities were highest in brown series $(70 \%)$ isolates. In other group of isolates; about $63.6 \%$ of the gray series, $50.0 \%$ of white series, $58.3 \%$ orange series, and $50.0 \%$ of red series isolates exhibited a broad range of activity against the test bacteria. 
Table 1. Color Grouping of the Isolates.

\begin{tabular}{lllll}
\hline Color Group & Representative isolate & Color of aerial mycelia & Color of substrate mycelia & Diffusible pigment \\
\hline & ANAM-1 & Light brownish gray & Light gray & Not present \\
& ANAM-4 & Brownish gray & Yellowish gray & Not present \\
& ANAM-5 & Yellowish gray & Dusky red & Yellow \\
Group 1 & ANAM-12 & Deep yellowish gray & Grayish yellow & Not present \\
(Gray series) & ANAM-18 & Very light gray & Pinkish gray & Not present \\
& ANAM-19 & Pinkish gray & Light gray & Not present \\
& ANAM-23 & Yellowish gray & Yellowish brown & Not present \\
& ANAM-36 & Reddish gray & Pinkish gray & Not present \\
& ANAM-38 & Yellowish gray & Grayish yellow & Yellow \\
& ANAM-48 & Darkish gray & Dark & Not present \\
& ANAM-2 & Pinkish brown & Yellowish gray & Not present \\
ANAM-7 & Light brown & Grayish yellow & Not present \\
(Brown & ANAM-16 & Deep brown & Light yellow & Not present \\
series) & ANAM-17 & Grayish brown & Grayish yellow & Not present \\
& ANAM-21 & Dark yellowish brown & Light yellow & Not present \\
& ANAM-25 & Light brown & Light gray & Not present \\
& ANAM-26 & Deep yellowish brown & Yellowish gray & Not present \\
& ANAM-33 & Deep yellowish brown & Light brown & Not present \\
\hline
\end{tabular}

Table 2. Color Grouping of the Isolates.

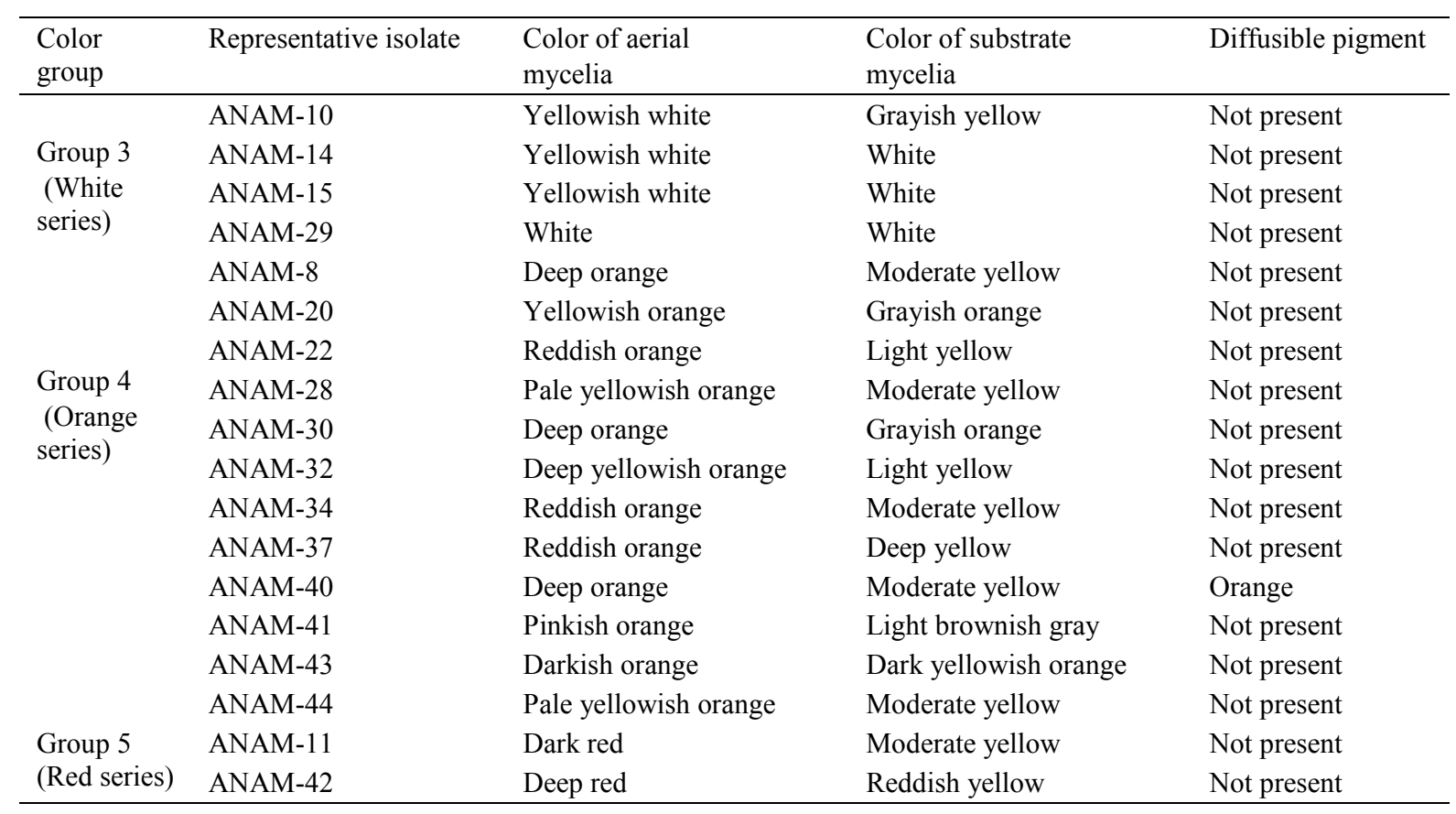

In gray series of isolates, two isolates (ANAM-5 and ANAM-38) showed highest antibacterial activity against most of the test bacteria but ANAM-38 was inactive against Staphylococcus aureus. ANAM-36 and ANAM-48 were moderately active against all of the test organisms. ANAM-1, ANAM-18 and ANAM-23 exhibited almost lowest activity against most of the organisms or inactive against some of the test organisms. 


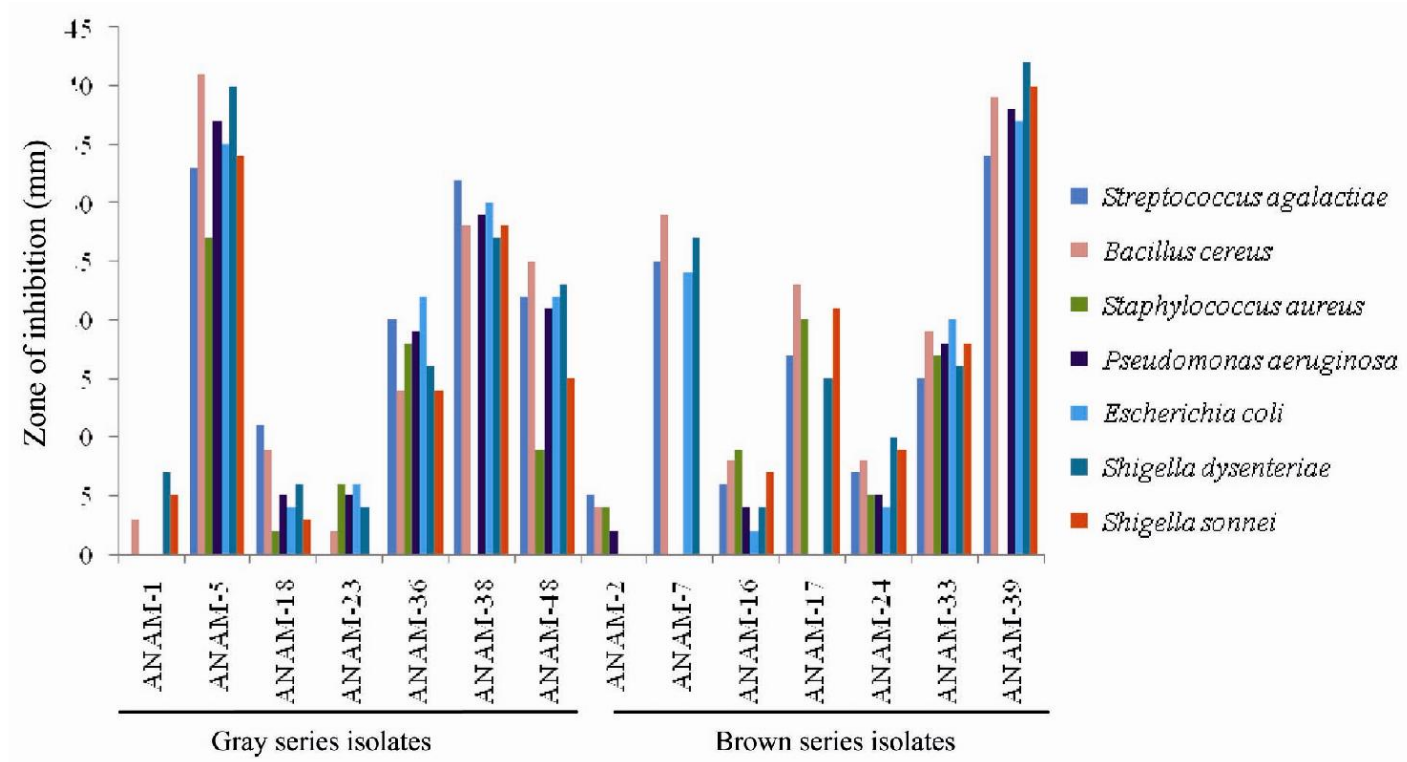

Figure 1. Antibacterial activities of gray and brown series isolates (only active isolates have been shown).

Table 3. Zone of inhibition (in $\mathrm{mm}$ ) of the Gray and Brown series isolates against a wide range of test bacteria (only active isolates have been shown).

\begin{tabular}{clccccccc}
\hline Color froup & $\begin{array}{l}\text { ID number of } \\
\text { the isolates }\end{array}$ & $\begin{array}{c}\text { Streptococcus } \\
\text { agalactiae }\end{array}$ & $\begin{array}{c}\text { Bacillus } \\
\text { cereus }\end{array}$ & $\begin{array}{c}\text { Staphylo- } \\
\text { coccus } \\
\text { aureus }\end{array}$ & $\begin{array}{c}\text { Pseudo- } \\
\text { monas } \\
\text { aeruginosa }\end{array}$ & $\begin{array}{c}\text { Escherichia } \\
\text { coli }\end{array}$ & $\begin{array}{c}\text { Shigella } \\
\text { dysenteriae }\end{array}$ & $\begin{array}{l}\text { Shigella } \\
\text { sonnei }\end{array}$ \\
\hline \multirow{5}{*}{ Group 1 } & ANAM-1 & 0 & 03 & 0 & 0 & 0 & 07 & 05 \\
(Gray series) & ANAM-5 & 33 & 41 & 27 & 37 & 35 & 40 & 34 \\
& ANAM-18 & 11 & 09 & 02 & 05 & 04 & 06 & 03 \\
& ANAM-23 & 0 & 02 & 06 & 05 & 06 & 04 & 0 \\
& ANAM-36 & 20 & 14 & 18 & 19 & 22 & 16 & 14 \\
& ANAM-38 & 32 & 28 & 0 & 29 & 30 & 27 & 28 \\
& ANAM-48 & 22 & 25 & 09 & 21 & 22 & 23 & 15 \\
& ANAM-2 & 05 & 04 & 04 & 02 & 0 & 0 & 0 \\
Group 2 & ANAM-7 & 25 & 29 & 0 & 0 & 24 & 27 & 0 \\
(Brown & ANAM-16 & 06 & 08 & 09 & 04 & 02 & 04 & 07 \\
& ANAM-17 & 17 & 23 & 20 & 0 & 0 & 15 & 21 \\
& ANAM-24 & 07 & 08 & 05 & 05 & 04 & 10 & 09 \\
& ANAM-33 & 15 & 19 & 17 & 18 & 20 & 16 & 18 \\
& ANAM-39 & 34 & 39 & 0 & 38 & 37 & 42 & 40 \\
\hline
\end{tabular}

On the other hand, ANAM-17 was inactive against Pseudomonas aeruginosa and Escherichia coli. ANAM-2, ANAM-16 and ANAM-24 were less active against most of the test bacteria. In white series of isolates, activity of two isolates (ANAM-10 and ANAM-14) showed low activity against all of the test bacteria while the isolate ANAM-10 could not inhibit Shigella sonnei.

In orange series isolates, all of the test organisms were moderately inhibited by two isolates (ANAM- 8 and
ANAM-40) but the test organism Staphylococcus aureus was not inhibited by isolate ANAM-40. ANAM-22 inhibited the entire test organism moderately. ANAM-28, ANAM-32 and ANAM-43 exhibited low to moderate activity against all the test bacteria except Staphylococcus aureus. ANAM-34 showed low activity against Streptococcus agalactiae and Escherichia coli but showed moderate inhibitory activity in case of Pseudomonas aeruginosa. On the other hand this isolate was inactive 
against Bacillus cereus, Staphylococcus aureus, Shigella dysenteriae and Shigella sonnei. Only one isolate, ANAM-11 of red series isolates exhibited highest and moderate activity against Streptococcus agalactiae and
Escherichia coli, respectively but this strain showed no activity against Bacillus cereus, Staphylococcus aureus, Pseudomonas aeruginosa, Shigella dysenteriae and Shigella sonnei.

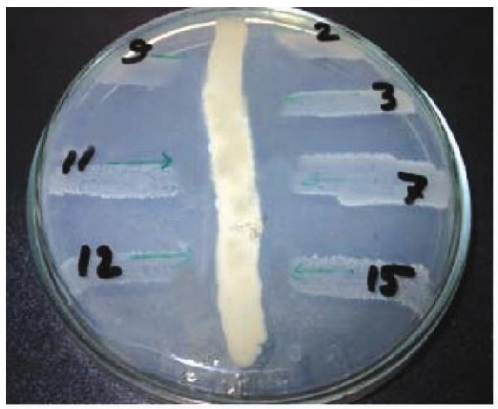

(a) ANAM-18

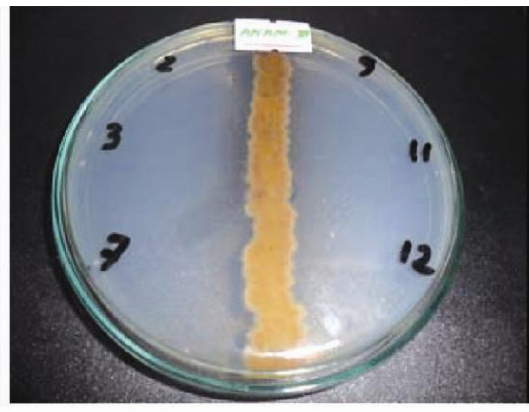

(b) ANAM-39

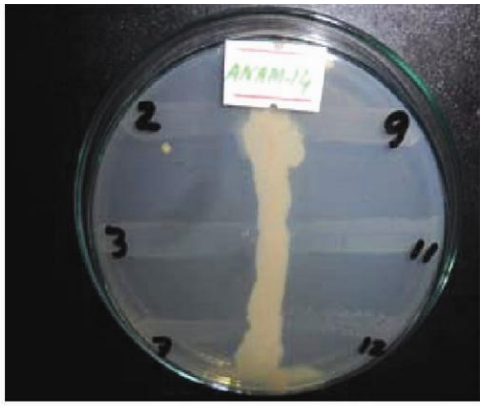

(c) ANAM-14

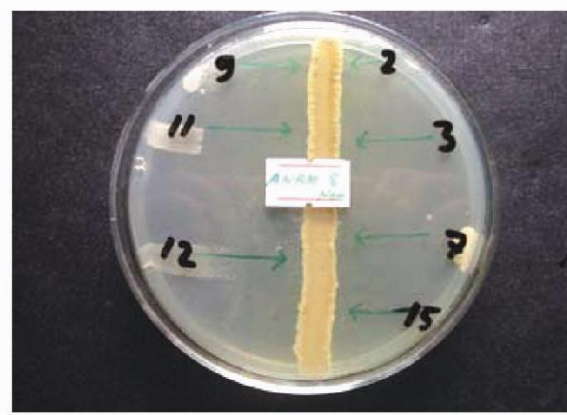

(d) ANAM-8

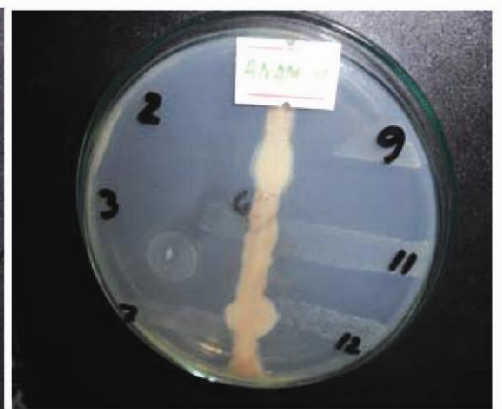

(e) ANAM-11

Figure 2. Antibacterial activity of representative isolates of different color series by streak-plating technique (A) ANAM-18, gray series, (B) ANAM-39, brown series, (C) ANAM-14, white series, (D) ANAM-8, orange series, (E) ANAM-11, red series. The perpendicular lines marked with numerical digits are the test organism- 2: Streptococcus agalactiae; 3: Bacillus cereus; 15: Staphylococcus aureus; 7: Pseudomonas aeruginosa; 9: Escherichia coli; 11: Shigella dysenteriae; 12: Shigella sonnei.

Table 4. Zone of inhibition (in $\mathrm{mm}$ ) of the White, Orange and Red series isolates against a series of test bacteria (only active isolates have been shown).

\begin{tabular}{|c|c|c|c|c|c|c|c|c|}
\hline Color group & $\begin{array}{l}\text { ID number of } \\
\text { the isolates }\end{array}$ & $\begin{array}{l}\text { Streptococcus } \\
\text { agalactiae }\end{array}$ & $\begin{array}{c}\text { Bacillus } \\
\text { cereus }\end{array}$ & $\begin{array}{c}\text { Staphylo- } \\
\text { coccus } \\
\text { aureus }\end{array}$ & $\begin{array}{l}\text { Pseudomo- } \\
\text { nas } \\
\text { aeruginosa } \\
\end{array}$ & $\begin{array}{c}\text { Escherichia } \\
\text { coli }\end{array}$ & $\begin{array}{c}\text { Shigella } \\
\text { dysenter } \\
\text { iae }\end{array}$ & $\begin{array}{r}\text { Shigella } \\
\text { sonnei }\end{array}$ \\
\hline Group 3 & ANAM-10 & 08 & 05 & 06 & 10 & 09 & 04 & 0 \\
\hline (White series ) & ANAM-14 & 05 & 04 & 05 & 07 & 12 & 13 & 03 \\
\hline Group 4 & ANAM-8 & 23 & 27 & 28 & 28 & 27 & 29 & 18 \\
\hline \multirow{6}{*}{ (Orange series ) } & ANAM-22 & 11 & 14 & 12 & 06 & 05 & 08 & 15 \\
\hline & ANAM-28 & 10 & 15 & 0 & 05 & 13 & 05 & 03 \\
\hline & ANAM-32 & 08 & 15 & 0 & 15 & 05 & 21 & 09 \\
\hline & ANAM-34 & 04 & 0 & 0 & 22 & 04 & 0 & 0 \\
\hline & ANAM-40 & 31 & 28 & 0 & 29 & 27 & 31 & 28 \\
\hline & ANAM-43 & 17 & 15 & 0 & 18 & 11 & 19 & 12 \\
\hline $\begin{array}{l}\text { Group } 5 \\
\text { (Red series ) }\end{array}$ & ANAM-11 & 33 & 0 & 0 & 0 & 10 & 0 & 0 \\
\hline
\end{tabular}

Marine microorganisms are considered as a storehouse of bioactive metabolites with tremendous potential as drug candidates. Secondary metabolites from marine microorganisms are considered to be a burning area of research since recent past. The present study was aimed to isolate bacteria from marine environment having the po- 
tentiality to produce antibacterial metabolites. Nine marine soil samples were collected very carefully from various locations of Sundarbans and thirty nine pure marine bacterial strains were isolated by using starch-casein-nitrateagar media.

For comparison we examined our study with other similar isolation study. We found that in a study which was carried out by Arifuzzaman et al. (2010), isolated 55 different bacteria from Sundarbans region, Bangladesh and screened them for antibacterial activity. After this screening work, they found that 20 isolates $(36.36 \%)$ were active against the test bacteria. In a different study, 30 Actinomycetes strain were isolated from soil samples collected from the different places of Rajshahi District, Bangladesh and the isolates were found to have a broad spectrum of antibacterial activity $53.3 \%$ (16 out of 30 ) of the total pure isolates (Rahman et al., 2011).

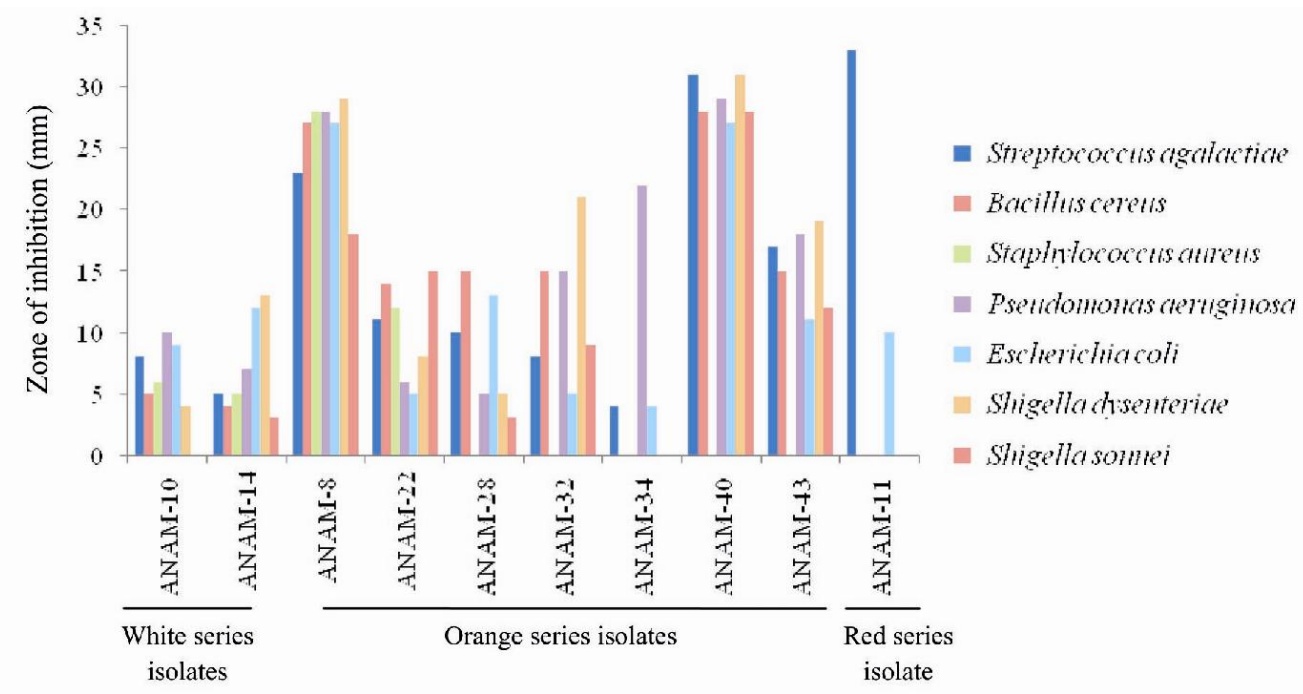

Figure 3. Antibacterial activities of white, orange and red series isolates (only active isolates have been shown).

In another study, from soils of north Jordan 90 different Streptomyces were isolated and $54 \%$ of the isolates were found to be active against test microorganisms (Saadoun et al., 1999). A study was performed by Abdelghani et al., (2009) where 51 Actinomycetes isolates were isolated from soil samples of Palestine and only 17 isolates (33.33\%) showed antibacterial activity against the test organism.

Recently, in a study which was carried out by Ramazani et al. (2013), isolated 229 different bacteria strains and performed antibacterial screening of the isolates. After this screening, they found that 154 isolates (67.24\%) showed antibacterial activity against a series test microorganism. In a different study, from soil samples collected from Manisa Province, 50 Actinomycetes strain were isolated and a broad spectrum of antibacterial activity $34 \%$ ( 17 out of 50 ) of the total pure isolates (Oskay et al., 2004) were showed by the isolates.
Comparing our study with the above mentioned results, we can conclude that the marine soil samples of Sundarbans are rich source of bacteria which have the potential to act as sources of new antibacterial compounds against pathogenic microorganisms to humans. In our study, we found that $61.5 \%$ of the isolated marine bacterial strains were active against the test bacteria. Two marine bacteria, ANAM-5 and ANAM-39 exhibited very large zone of inhibition. These marine isolates will be further investigated for their identification to species level and to identify the antibacterial compounds produced by them.

The haunt for novel metabolites requires a large number of isolates in order to discover a novel compound of pharmaceutical and pharmacological interest. The search will be more promising if diverse bacteria are screened. The ultimate goal of this present work was to isolate potent marine bacteria from Sundarbans soil sample to elucidate their antimicrobial activity. Results of this study indicate that the potential of the Sundarbans as a source of 
marine bacteria to produce antibacterial compounds that can be useful for many pharmaceutical applications and must be explored.

\section{Conclusion}

The present study was undertaken to isolate potent bacteria producing antibacterial metabolites from marine environment of Sundarbans. In our study, we found that $61.5 \%$ of the isolated pure colonies were active against the series of test bacteria. Thus, the results of the present research reveal that the marine bacteria from Sundarbans region is a potent source of novel antibacterial compounds and this marine environment warrants particular attention, for its remarkable microorganisms diversity and metabolic products. Two isolates (ANAM-5 and ANAM-39) exhibited highest antibacterial activity in terms of very large zone of inhibition. In order to identify these active isolates up to species level and antibacterial metabolites secreted by these isolates future study will be done.

\section{Acknowledgements}

This study was supported by Pharmaceutical Microbiology Laboratory, Department of Pharmacy, University of Rajshahi, Faculty of Science, Rajshahi-6205, Bangladesh.

\section{References}

Abdelghani, T., Kurad, B.R. and Poluri, E. 2009. Antibacterial activity of bacterial isolates of soil bacteria collected from Palestine. Cur. Trends Biotech. Pharm. 2, 275-281.

Alcamo, E. and Pomerville, J.C. 2004. Alcamo's Laboratory Fundamental of Microbiology. $7^{\text {th }}$ Edn, Jones \& Bartlett Publishers, London.

Anderson, A.S. and Wellington, E.M.H. 2001. "The taxonomy of Streptomyces and related genera," Int. J. Syst. Evolu. Microbiol. 3, 797-814.

Arifuzzaman, M., Khatun, M.R and Rahman, H. 2010. Isolation and screening of Actinomycetes from Sundarbans soil for antibacterial activity, Afr. J. Biotech. 29, 4615-4619.

Bhatnagar, I. and Kim, S. 2010. Immense Essence of Excellence: Marine Microbial Bioactive Compounds. Mar. Drugs. 8, 2673-2701.

Guskey, M.T. and Tsuji, B.T. 2010. A comparative review of the lipoglycopeptides: oritavancin, dalbavancin and telavancin. Pharmacotherapy 30, 80-94.

Hong, K., Gao, A.H., Xie, Q.Y., H. Gao, H., Zhuang, L., Lin, H.P., Yu, H.P., Li, J., Yao, X.S. and Ruan, J.S. 2009. Actinomycetes for marine drug discovery isolated from mangrove soils and plants in China. Mar. Drugs.1, 24-44.
Jaiganesh, R. and Kumar, N.S.S. 2012. Marine bacterial sources of bioactive compounds. Adv. Food Nutr. Res. 65, 389-408.

Kampfer, P. 2006. "The Family Streptomycetaceae, Part I: Taxonomy", The prokaryotes: a handbook on the biology of bacteria. Berlin: Springer. 51, 538-604.

Manivasagan, P., Venkatesan, J., Sivakumar, K. and Kim, S.K. 2013. Marine actinobacterial metabolites: current status and future perspectives. Microbiol. Res. 6, 311-32.

Manivasagan, P., Venkatesan, J., Sivakumar, K. and Kim, S.K. 2014. Pharmaceutically active secondary metabolites of marine actinobacteria. Microbiol. Res. 4, 262-78.

Maragakis, L.L., Perencevich, E.N. and S.E. Cosgrove, S.E. 2008. Clinical and economic burden of antimicrobial resistance. Expert Rev. Anti Infect. Ther. 6, 751-763.

Nawani, N., Aigle, B., Mandal, A., Bodas, M., Ghorbel, S. and Prakash, D. 2013. Actinomycetes: Role in Biotechnology and Medicine. BioM. Res. Inter. 7, 1-7.

Nonomura and Ohara. 1969. Developing a new resource for drug discovery. Mar. actin. 9, 79-105.

Oskay, M., Tamer, A.U. and Azeri, C. 2004. Antibacterial activity of some Actinomycetes isolated from farming soils of Turkey. Afr. J. Biotech. 9, 441-446.

Raghunath, D. 2008. Emerging antibiotic resistance in bacteria with special reference to India. J. Biosci. 33, 593-603.

Rahman, M.A., Islam, M.Z. and Islam, M.A.U. 2011. Antibacterial activities of actinomycete isolates collected from soils of Rajshahi, Bangladesh. Biotech. Res. Inter. 11, 123-138.

Ramazani, A., Moradi, S., Sorouri, R., Javan, S. and Garshasbi, M. 2013. Screening for antibacterial activity of streptomyces species isolated from zanjan province, Iran, Inter. $J$. Pharm. Chem. Bio. Sci. 2, 342-349.

Saadoun, I., Momani, F., Malkawi, H.I. and Mohammad, M.J. 1999. Isolation, identification and analysis of antibacterial activity of soil streptomycetes isolates from north Jordan. Microbios. 395, 41-6.

Shomura, T., Omoto, S.M., Ohba, K. and Ogino, H. 1980. "SF1961, a new antibiotic related to bleomycin. J. Antibio. 11, $1243-1248$

Singer, R.S., Finch, R., Wegener, H.C., Bywater, R., Walters, J. and Lipsitch, M. 2003. Antibiotic resistance-the interplay between antibiotic use in animals and human beings. $T$. Lan. Infect. Dis. 3, 47-51.

Sivasubramanian, K., Ravichandran, S. and Vijayapriya, M. 2011. Antagonistic activity of marine bacteria Pseudoalteromonas tunicata against microbial pathogens. Afr. J. Micro. Res. 5, 562-567.

Valli, S., Sugasini, S.S., Aysha, O.S., Nirmala, P., Kumar, P.V. and Reena, A. 2012. Antimicrobial potential of Actinomycetes species isolated from marine environment. As. Pac. J. Trop. Biomed. 6, 469-473.

Zhao, H., Parry, R.L., Fllis, D.L., Griffith, G.W. and Goodacre, R. 2006. The rapid differentiation of Streptomyces isolates using fourier transform infrared spectroscopy. Vibra. Spec. 40, 213-218. 